\title{
Accelerator-Driven System Options: Value Analysis and Practical Implications
}

\author{
Vitaly Pronskikh \\ Fermi National Accelerator Laboratory
}

International Round Table on Applied Research and Innovations @ NICA, September 15-16, 2021 


\section{Contemporary problems of nuclear power}

- Depletion of resources (uranium)

- Accumulation of nuclear waste

- Radiation safety (public and personnel)

- Nuclear safety and security issues (based on values)

- Related ethical issues :

- inter- and intragenerational justice (Pure Intergenerational Problem, Gardiner): resources, accumulation, processing and disposal of nuclear waste

- The problem of identity of future generations (non-identity problem Parfit)

- Deontology and utilitarianism in the assessment of the permissible dose

- Gender Equity in Radiation Safety

Applied ethics underpins the social assessment of technology (SAT).

SAT must be assigned in nuclear technologies the same role as bioethics plays in life sciences 


\section{The problem of choosing a nuclear fuel cycle (NFC)}

- Open fuel cycle (once-through cycle): fuel is loaded into reactors once, after which spent nuclear fuel (SNF, nuclear waste) is disposed of in long-term storage facilities.

$\checkmark$ SNF remains radiotoxic for $\sim 200,000$ years; after extraction of plutonium and other transuranic elements for $\sim 10,000$ years

$\checkmark$ Used in the USA, Sweden, Canada, Czech Republic

- Closed fuel cycle: After irradiation, components are extracted from SNF and used as fuel in other (for example, fast) reactors. Recycling fuel can make it radiotoxic for 200-500 years. It is possible to "burn out" spent nuclear fuel in "fast reactors" (Russia, Beloyarsk NPP) (increases the durability of resources)

$\checkmark$ Used in Russia, India, Japan, China

- A closed cycle poses more risks for the current and the nearest generations, an open cycle for the uncertain future ones (I dub them Western and Eastern approaches) 


\section{Ethical dilemmas of the nuclear fuel cycle}

- Dilemma (S. Gardiner): On the one hand, it is beneficial for each generation to save resources and pass them on to other generations; on the other hand, for each separate generation it is beneficial to use the available resources to the maximum for their own purposes.

- B. Barry: someone's belonging to a certain generation cannot justify violating their vital interests

- Parfit: Abrupt living conditions changes in the present (for example, energy production restrictions) can affect future generations and their identities (descendants will be different). (The non-identity problem is a contradiction with B. Taebi: the humankind needs to reduce uranium mining as much as possible)

- Avoiding drastic changes and increased risks for the current generation maintaining current technologies - benefits of the open NFC

- How important are the interests of future generations (and which generations)? 


\section{How important are the interests of future}

generations?

- Little can be said about the identity of future generations:

$\checkmark$ Greatest empathy for the next 5 generations (150 years)

$\checkmark$ Identity cannot be predicted beyond 300 years (Taebi)

$\checkmark$ Future generations may be more technologically advanced (example of electric lighting)

$\checkmark$ By choosing the open NFC, we recognize one of two possibilities: future generations will either have a different identity (and thus will be indifferent to us), or they will be more technologically advanced and independently find ways to solve the problem of nuclear waste

$\checkmark$ By choosing the closed NFC, we create more risks for the current generation (and, therefore, future ones), but we save resources

$\checkmark$ Both NFCs pose threats to out values 


\section{Values and threats}

- Values: future nuclear energy option design should meet the values of environmental friendliness, public safety, security, safeguards, resource durability, and economic viability (B.Taebi)

- Environmental and public safety threats, which arise at all stages of nuclear fuel mining and fabrication, operation of nuclear power station, its decommissioning, recycling, and spent fuel storage and disposal. There threats are related to possible accidents resulting in contamination of environment as well as human exposure to radiation at these stages of nuclear fuel and waste management.

- Security threats are related to the same stages of mining, nuclear power station operation, decommissioning, and waste recycling and disposal, but are associated with illegal theft of nuclear materials at these stages of management of nuclear materials, and sabotage resulting in dispersal of radioactive material.

- Safeguards threats. These threats exist at the same stages of management of nuclear materials as above, but are related to possibility removal of fissile material from declared holdings, removal of other nuclear material (that the state could then use to secretly produce fissile material), and undeclared use of a fuel-cycle facility to produce fissile material. 


\section{Threats in ADS options and FBR}

The major threats of ADS and FBR and fundamental questions of the NFCs:

- NFCs that use technologies for the extraction of groups of isotopes from spent fuel significantly increase risks

- Breeding of weapons-grade plutonium: security and safeguards threats

- FP are not transmuted thus the threats for the nearest generations $<200-500$ year from now are not eliminated

\begin{tabular}{|c|c|c|c|c|}
\hline Option type & FBR & $\begin{array}{l}\text { ADS Pb+Bi/ } \\
\text { MOX }\end{array}$ & $\begin{array}{l}\text { ADS Pb+Bi/ } \\
\text { MA }\end{array}$ & ADS MA/MA \\
\hline \multicolumn{5}{|c|}{ Environmental/Public Safety } \\
\hline \multicolumn{5}{|l|}{ threats } \\
\hline Mining, fuel fabrication & Medium & Medium & Medium & Medium \\
\hline Transport of fuel & Medium & Medium & Medium & Low \\
\hline ADS/FBR operation & High & Low & Low & Low \\
\hline ADS/FBR decommissioning & High & High & High & High \\
\hline Spent fuel storage & High & Medium & Medium & Low \\
\hline Final disposal of spent fuel & Medium & Low & Low & Low \\
\hline Final disposal of other waste & N/A & Medium & Medium & Medium \\
\hline Recycling of spent fuel & High & Medium & Medium & Low \\
\hline \multicolumn{5}{|l|}{ Security threats } \\
\hline Mining, fuel fabrication & High & High & Medium & Medium \\
\hline Transport of fuel & High & High & Medium & Medium \\
\hline ADS/FBR operation & Medium & Medium & Medium & Medium \\
\hline ADS/FBR decommissioning & High & High & Medium & Medium \\
\hline Spent fuel storage & High & Medium & Medium & Low \\
\hline Final disposal of spent fuel & High & Low & Low & Low \\
\hline Final disposal of other waste & N/A & High & Medium & Medium \\
\hline Recycling of spent fuel & High & Medium & Medium & Low \\
\hline \multicolumn{5}{|c|}{ Safeguards threats } \\
\hline Mining, fuel fabrication & High & High & Medium & Medium \\
\hline Transport of fuel & Medium & Medium & Medium & Medium \\
\hline ADS/FBR operation & High & High & Medium & Medium \\
\hline ADS/FBR decommissioning & High & High & High & High \\
\hline Spent fuel storage & High & Medium & Medium & Low \\
\hline Final disposal of spent fuel & High & Low & Low & Low \\
\hline Final disposal of other waste & N/A & High & Medium & Medium \\
\hline Recycling of spent fuel & High & Medium & Medium & Low \\
\hline
\end{tabular}

From V.Pronskikh and B.Taebi, NAPAC'16 (preliminary) 


\section{Important research directions for accelerator centers: a demonstrator}

- Studies of ADS technologies with a minimized plutonium breeding

- There are indications that in some configurations ADS-like target cores produce less plutonium than burn.

- Studies are needed for systems with a blanket/or a full absorption one

- "the production rate of ${ }^{238} \mathrm{Pu}$ from ${ }^{237} \mathrm{~Np}$ does not exceed its incineration by means of fission." L. Zavorka et al., Nuclear Instruments and Methods in Physics Research B 349 (2015) 31-38

- Will this be the case for a prototype with a blanket?
Studies of FP transmutation

- A rather longterm (>300 years) radiotoxicity of FP does not allow to benefit from the implementation of ADS or FBR NFC technologies in the sense of addressing the Gardiner dilemma (intergenerational justice)

- Chiba, S et al. Sci Rep 7, 13961 (2017): reduced effective half-lives of LLFP to 100 years in a FBR with an yttrium deuteride blanket.

- To compare: FBR (710 MWt) transmutes 129l at 60\% @ 18 years (@ 2GeV Nuclotron "QUINTA" - 18\%@18 years $(10 \mathrm{~mA})$ ). 


\section{Conclusion}

- Nuclear power development and related issues (durability of resources, waste, radiation safety) lead to nuclear fuel cycle dilemmas :

- Open NFC (once-through): safer for the current generation, but produces nuclear waste hazardous to future ones

- Closed NFC: more resource-efficient, poses more risks for the current generation, less for the future ones

- Open NFC - more risks for distant generations, closed NCF - more risks for everyone

- Common threats for our values from both types of NFC: 1) breeding of plutonium; 2) accumulation of LLFP.

- Priority ADS studies needed with demonstrators: 1) plutonium production/incineration balance; 2) LLFP transmutation rates. Various moderators need to be explored. 